\title{
Insight of Prevalence, Toxin Typing and Antimicrobial Susceptibility of Egyptian Clostridium perfringens Isolates Recovered from Broiler, Layer and Breeder Chicken Flocks
}

\author{
Mustafa Bastamy ${ }^{1}$, Ismail Raheel ${ }^{2}$, Hany Ellakany ${ }^{3}$, Ahmed Samir ${ }^{4}$, Mohamed Hamoud ${ }^{1}$, Rabab \\ Amin Khalifa ${ }^{5}$, Samar Ibrahim, Samer Abd El rahman ${ }^{6}$ and Ahmed Orabi ${ }^{4 *}$
${ }^{1}$ Department of Poultry and Rabbit Diseases, Faculty of Veterinary Medicine, Cairo University, Egypt
${ }^{2}$ Department of Bacteriology, Mycology and Immunology, Faculty of Veterinary Medicine, Beni-Suief University, Egypt ${ }^{3}$ Department of Poultry and Fish Diseases, Faculty of Veterinary Medicine, Damanhour University, Egypt
${ }^{4}$ Department of Microbiology, Faculty of Veterinary Medicine, Cairo University, Egypt, Cairo, Egypt
${ }^{5}$ Poultry Company (CPC) Lab, Cairo, Egypt; ${ }^{6}$ Faculty of Veterinary Medicine, Beni-Suief University, Egypt
*Corresponding author: drorabi2012@yahoo.com; Orabivet@cu.edu.eg

Article History: 21-349 Received: 06-Jul-21 Revised: 22-Jul-21 Accepted: 26-Jul-21
A BST RA C T
Clostridial infection is associated with significant health problems in poultry today, as its enteritis affects intestinal
integrity in poultry flocks and may cause considerable losses, which caused by Clostridium perfringens that found all
over the world, so fighting this infection is a continuing challenge for the poultry sector. Preventive actions using
dedicated products are a valuable solution to maintain healthy gut flora. In this study the prevalence of $C l o s t r i d i u m$
perfringens was detected in different chicken flocks at a rate of $32 \%$. Also, toxin-typing showed presence of $c p a$, $c p b$,
etx, iap and $c p$ e toxins among the isolates which mainly associated with necrotic enteritis cases. Net- $B$ toxin is a novel
toxin that had been recently identified in virulent avian $C$. perfringens isolates and it presence potentiate the necrotic
lesions and destroy the enterocytes. Antimicrobial patterns showed high resistance against most common antibacterial
drugs as $\beta$-lactams, aminoglycosides, macrolides and tetracyclines. NetB toxin harboring isolates, originating from
diseased broiler, layer and breeder chickens showed the lowest minimum inhibitory concentration MICs values for the
penicillin from $\beta$-lactams and tylvalosin from macrolides.

Key words: Clostridium perfringens, Net-B toxins, Chicken flocks, MICs, Penicillin.

\section{INTRODUCTION}

Clostridium belongs to Clostridiaceae family which contains more than 203 species. Clostridium perfringens (C. perfringens) is the most commonly isolated species, which is classified to five types according to major lethal toxins they produce (Koneman et al. 1997). Clostridium diagnosis at bacteriological and molecular base still difficult till now for several reasons, including their specific growth (Collins et al. 1994). Clinically the important Clostridium species that associated are with clinical aspects in humans, animals and birds ranged from 40-50 species that produce a variety of toxins which leads to the distinctive clinical features of the diseases they cause (Hatheway 1990). PCR-based methods for $C$. perfringens genotypes are accumulating as more diagnostic and research laboratories adopt for toxin gene detection. There were various genotypes by geographic region, although $C$. perfringens type A remains the most commonly isolated type overall (Garmory et al. 2000), which act as the causative agent of necrotic enteritis, and its clinical form is most often seen in broilers but may also be seen in broiler breeders and layers kept on litter system, while subclinical form appear in the intestine and liver. The disease is characterized by distinct ulcers and necrosis in the mucosa of the anterior small intestine and hepatitis (Fossum et al. 1988; Kaldhusdal and Hofshagen 1992). C. perfringens-related hepatitis is characterized by cholangiohepatitis or focal necrosis in the liver and bile ducts, leading to obstruction of the bile ducts (Randall 1991), as the pathogens migrate from duodenum to liver through bile ducts or via liver veins (Sasaki et al. 2000).

Cite This Article as: Bastamy M, Raheel I, Ellakany H, Samir A, Hamoud M, Khalifa RA, Ibrahim S, El Rahman SA and Orabi A, 2022. Insight of prevalence, toxin typing and antimicrobial susceptibility of Egyptian Clostridium perfringens isolates recovered from broiler, layer and breeder chicken flocks. International Journal of Veterinary Science 11(1): 110-116. https://doi.org/10.47278/journal.ijvs/2021.080 
Virulent $C$. perfringens isolates produce 16 protein toxins that are important for the development of different diseases, such as food poisoning, antibiotic associated diarrhea, fatal gas gangrene, enterotoxaemia, and hemorrhagic gastroenteritis (Jihong et al. 2016). $C$. perfringens $\alpha$-toxigenic strains of are the most common type isolated from chickens suffering from necrotic enteritis (Timbermont et al. 2009), but recently netB is a new toxin, in avian $C$. perfringens type A strains (Keyburn et al. 2008). Alpha toxin is a phospholipase that hydrolyzes phospholipids and promotes membrane disorganization, also hydrolysis of lecithin results in stimulation of the arachidonic acid cascade that induces the synthesis of inflammatory mediators which causes blood vessel contraction, platelet aggregation and myocardial dysfunction, leading to acute death, while beta toxin induces hemorrhagic necrosis of the intestinal mucosa (Titball et al. 2000; Awaad et al. 2019). The most common predisposing factors for NE include environmental stress, high stocking density, concurrent infection with IBD and coccidiosis, high protein and fat levels in diet change in mucus production and gut transit time and other dietary factors including lectins, trypsin inhibitors, tannins and mycotoxins (Prescott et al. 2016), so NE has been controlled by reducing exposure to risk factors such as coccidiosis, unsuitable diets and adding antibiotics in the feed and water of poultry (Gabriel et al. 2003). Unfortunately, antibiotic resistance in bacteria may make the commonly used antibiotics less effective (Yegani and Korver 2007), so antibiotic growth promoters (AGPs) have been banned from animal feed worldwide to avoid the spread of antimicrobial resistance and this has contributed to the higher prevalence of economically important diseases such as necrotic enteritis (Van Immerseel et al. 2009). The present study aimed to assess the prevalence of netB harboring $C$. perfringens among Egyptian chicken flocks either broiler, or breeder with special attention to its antimicrobial susceptibility and minimum inhibitory concentration.

\section{MATERIALS AND METHODS}

\section{Isolation and Identification of $C$. Perfringens}

During 2020, three hundred intestinal contents of enteritis lesions from broiler $(n=160)$, layer $(n=100)$ and breeder $(\mathrm{n}=50)$ chicken's suspected cases from 40 flocks (broilers $(n=25)$, layer $(n=30)$ and breeder $(n=10)$ were inoculated into tryptone proteose peptone glucose, then transfer to fluid thioglycollate (Becton, Dickinson, USA) and plated onto TSC agar (Oxoid, UK) at $37^{\circ} \mathrm{C}$ in an anaerobic condition (Martin et al. 2009). Colonies were further sub-cultured on sheep blood agar and checked visually for double-hemolysis zone surrounding the colonies of $C$. perfringens and confirmed biochemically using API 20 A Anaerobes system. The recovered isolates bacterial suspensions were then frozen in BHI broth with $20 \%$ glycerol at $-80^{\circ} \mathrm{C}$ (Quinn et al. 2011).

\section{C. perfringens Toxin Typing by using PCR Assay}

The boiling technique according to Kanakaraj et al. (1998), was used to extract DNA from the isolates and the primers for toxins typing were $c p a, c p b$, etx, iap, cpe according to Yoo et al. (1997), while netB toxin primers were used according to Datta et al. (2014) at which selected $n e t B$ toxin positive isolates were sequenced and accessed on Genbank from broiler, and breeder chicken flocks.

\section{Antimicrobial Susceptibility Testing}

Agar disc diffusion method were used for tested antimicrobial susceptibility $C$. perfringens strains at $37^{\circ} \mathrm{C}$ overnight in anaerobic conditions using the following antimicrobial agents (Oxoid, Hampshire, UK) were tested: penicillin $\mathrm{G}(10 \mathrm{U})$, penicillin $\mathrm{V}(30 \mu \mathrm{g})$, ampicillin $(10 \mu \mathrm{g})$, amoxicillin $(20 \mu \mathrm{g})$, ceftifur $(30 \mu \mathrm{g})$, bacitracin $(10 \mu \mathrm{g})$, lincomycin $(30 \mu \mathrm{g})$, florphenicol $(30 \mu \mathrm{g})$, clindamycin $(2 \mu \mathrm{g})$, erythromycin $(15 \mu \mathrm{g})$, tylosin $(30 \mu \mathrm{g})$, tilmicosin $(15 \mu \mathrm{g})$, spiramycin $(100 \mu \mathrm{g})$, tylvalosin $(0.6 \mu \mathrm{g})$, flumequine $(30 \mu \mathrm{g})$, ciprofloxacin $(5 \mu \mathrm{g})$, enerofloxacin $(5 \mu \mathrm{g})$, difloxacin $(10 \mu \mathrm{g})$, oxytetracycline $(30 \mu \mathrm{g})$, doxycycline $(30 \mu \mathrm{g})$, metronidazole $(30 \mu \mathrm{g})$ rifampicin $(5 \mu \mathrm{g})$ vancomycin $(5 \mu \mathrm{g})$, colistin $(10 \mu \mathrm{g})$, neomycin $(30 \mu \mathrm{g})$, gentamycin $(10 \mu \mathrm{g})$, streptomycin $(10 \mu \mathrm{g})$, spectinomycin $(100 \mu \mathrm{g})$ and trimethoprim-sulfamethoxazole $(25 \mu \mathrm{g})$ (Perelman et al. 1991; BSAC 2011).

\section{Measuring MICs of Clostridium perfringens net- $B$ Toxins Isolates}

Brucella broth was used for broth micro dilution susceptibility testing. Refreshes of $C$. perfringens strains from frozen condition by subculture twice on TSA supplemented with 5\% defibrinated sheep blood followed by inoculation into brucella broth supplemented with Oxyrase to generate anaerobiosis. Inoculum was grown at $37^{\circ} \mathrm{C}$ for $24 \pm 12 \mathrm{~h}$ then diluted in brucella broth to a 0.5 McFarland turbidity standard. Sixteen antibiotics were obtained from Sigma (St Louis, MO) as the following: penicillinV and G, ampicillin, amoxicillin, ceftifur, bacitracin, lincomycin, tylosin, tilmicosin, tylvalosin, ciprofloxacin, enrofloxacin, difloxacin, flumequine, vancomycin, metronidazole and rifampicin and Stock solution prepared according to the guidelines of the producer. Stocks were either frozen or freshly prepared and subsequent dilutions of the stock solutions were performed using the procedure listed in NCCLS (CLSI 2018).

\section{Statistical Analysis}

Data were analyzed by with SPSS version 7.5 software. All values were expressed as the mean \pm SD. significant differences between the groups were statistically analyzed by one way analysis of variance (ANOVA). A statistical difference of $\mathrm{P}<0.05$ was considered significant.

\section{RESULTS}

The prevalence of $C$. perfringens during the different season of 2020 was $37 \%$ distributed as the following in broilers $(42 \%)$, layers $(38 \%)$ and breeders $(44 \%)$ with high incidence in autumn $(30 \%)$ followed in winter (26\%), spring (22\%) and summer (19\%). Toxin typing of the recovered isolates by using PCR assay revealed that cpa toxin in broilers (73\%), layers (79\%) and breeders $(68 \%)$. Whereas $c p b$ toxins was found in $25 \%$ broilers, $66 \%$ layers and $45 \%$ breeders. The etx toxin was detected in $14.5 \%$ broilers, $32 \%$ layers and $18 \%$ breeders. The iap toxin was noted in $27 \%$ broilers, $37 \%$ layers and $27 \%$ breeders. The cpe and netB toxin were found in 45 and $82 \%$ broilers, 53 and $89 \%$ layers and 45 and $90 \%$ breeders, respectively. 
Int J Vet Sci, 2022, 11(1): 110-116.

Table 1: Disk diffusion antimicrobial susceptibility of Egyptian C. perfringens isolates recovered from various chicken flocks

\begin{tabular}{|c|c|c|c|c|c|c|c|c|c|}
\hline \multirow[t]{2}{*}{ Antimicrobials } & \multicolumn{3}{|c|}{ Broilers $(n=55)$} & \multicolumn{3}{|c|}{ Layers $(n=38)$} & \multicolumn{3}{|c|}{ Breeders $(n=22)$} \\
\hline & $\mathrm{S} / \mathrm{R}$ & + No. & $+\%$ & $\mathrm{~S} / \mathrm{R}$ & + No. & $+\%$ & $\mathrm{~S} / \mathrm{R}$ & + No. & $+\%$ \\
\hline Penicillin G & $\mathrm{S}$ & 40 & 73 & $\mathrm{~S}$ & 28 & 74 & $\mathrm{~S}$ & 15 & 68 \\
\hline Penicillin V & S & 55 & 100 & S & 38 & 100 & S & 22 & 100 \\
\hline Ampicillin & S & 30 & 54.5 & S & 30 & 79 & $\mathrm{R}$ & 22 & 100 \\
\hline Amoxicillin & $\mathrm{S}$ & 45 & 82 & $\mathrm{~S}$ & 30 & 79 & $\mathrm{~S}$ & 18 & 82 \\
\hline Ceftifur & $\mathrm{S}$ & 25 & 45 & $\mathrm{~S}$ & 15 & 39 & $\mathrm{~S}$ & 12 & 55 \\
\hline Bacitracin & S & 25 & 45 & $\mathrm{R}$ & 20 & 53 & $\mathrm{R}$ & 15 & 68 \\
\hline Lincomycin & $\mathrm{S}$ & 25 & 45 & $\mathrm{R}$ & 20 & 53 & $\mathrm{R}$ & 15 & 68 \\
\hline Clindamycin & $\mathrm{R}$ & 55 & 100 & $\mathrm{R}$ & 28 & 74 & $\mathrm{R}$ & 22 & 100 \\
\hline Erythromycin & $\mathrm{S}$ & 15 & 27 & $\mathrm{R}$ & 38 & 100 & $\mathrm{R}$ & 22 & 100 \\
\hline Spiramycin & $\mathrm{R}$ & 55 & 100 & $\mathrm{R}$ & 38 & 100 & $\mathrm{R}$ & 22 & 100 \\
\hline Tylosin & $\mathrm{S}$ & 25 & 45 & $\mathrm{~S}$ & 18 & 47 & $\mathrm{~S}$ & 12 & 55 \\
\hline Tilmicosin & $\mathrm{S}$ & 20 & 37 & $\mathrm{~S}$ & 15 & 39 & $\mathrm{~S}$ & 10 & 45 \\
\hline Tylvalosin & $\mathrm{S}$ & 40 & 73 & $\mathrm{~S}$ & 25 & 66 & $\mathrm{~S}$ & 15 & 68 \\
\hline Ciprofloxacin & $\mathrm{S}$ & 15 & 27 & $\mathrm{R}$ & 38 & 100 & $\mathrm{R}$ & 22 & 100 \\
\hline Difloxacin & $\mathrm{S}$ & 15 & 27 & $\mathrm{R}$ & 38 & 100 & $\mathrm{R}$ & 22 & 100 \\
\hline Flumequine & S & 15 & 27 & $\mathrm{R}$ & 38 & 100 & $\mathrm{R}$ & 22 & 100 \\
\hline Oxytetracycline & $\mathrm{R}$ & 55 & 100 & $\mathrm{R}$ & 38 & 100 & $\mathrm{R}$ & 22 & 100 \\
\hline Doxycycline & $\mathrm{R}$ & 55 & 100 & $\mathrm{R}$ & 38 & 100 & $\mathrm{R}$ & 22 & 100 \\
\hline Chlortetracycline & $\mathrm{R}$ & 55 & 100 & $\mathrm{R}$ & 38 & 100 & $\mathrm{R}$ & 22 & 100 \\
\hline Vancomycin & S & 55 & 100 & S & 38 & 100 & $\mathrm{~S}$ & 22 & 100 \\
\hline Rifampicin & $S$ & 30 & 54.5 & $\mathrm{R}$ & 30 & 79 & $\mathrm{R}$ & 18 & 82 \\
\hline Metronidazole & $\mathrm{S}$ & 30 & 54.5 & $\mathrm{R}$ & 20 & 53 & $\mathrm{R}$ & 18 & 82 \\
\hline Colistin & $\mathrm{R}$ & 55 & 100 & $\mathrm{R}$ & 38 & 100 & $\mathrm{R}$ & 22 & 100 \\
\hline Florphenicol & $\mathrm{R}$ & 55 & 100 & $\mathrm{R}$ & 38 & 100 & $\mathrm{R}$ & 22 & 100 \\
\hline Spectinomycin & $\mathrm{R}$ & 55 & 100 & $\mathrm{R}$ & 38 & 100 & $\mathrm{R}$ & 22 & 100 \\
\hline Neomycin & $\mathrm{R}$ & 55 & 100 & $\mathrm{R}$ & 38 & 100 & $\mathrm{R}$ & 22 & 100 \\
\hline Gentamycin & $\mathrm{R}$ & 55 & 100 & $\mathrm{R}$ & 38 & 100 & $\mathrm{R}$ & 22 & 100 \\
\hline Streptomycin & $\mathrm{R}$ & 55 & 100 & $\mathrm{R}$ & 38 & 100 & $\mathrm{R}$ & 22 & 100 \\
\hline Trimethoprim-sulfamethoxazole & $\mathrm{R}$ & 55 & 100 & $\mathrm{R}$ & 38 & 100 & $\mathrm{R}$ & 22 & 100 \\
\hline
\end{tabular}

R: Resistant S: Susceptible.

Three netB toxin harboring $C$. perfringens strains were sequenced and accessed on Genbank under code: MW925054 from broiler, MZ382848 from layer and MW925055 from breeder chicken flock respectively. Antimicrobial susceptibility patterns by disk diffusion methods in Table 1 showed that the all recovered isolates were sensitive to penicillin, amoxicillin, tylvalosin and vancomycin, while were resistant for clindamycin, spiramycin, oxytetracycline, doxycycline, chlortetracycline, colistin, florphenicol, spectinomycin, neomycin, gentamycin, streptomycin and trimethoprim-sulfamethoxazole. The other antibiotics showed sensitivity against broiler isolates only as lincomycin, erythromycin, ciprofloxacin, enrofloxacin, difloxacin, flumequine and rifampicin. Also, there were some isolates sensitive to amoxicillin, ceftifur, tylosin, and tilmicosin. The minimum inhibitory concentration values "MICs $\mu \mathrm{g} / \mathrm{ml}$ ", of net-B toxin isolates recorded in (Table 2) which showed that the lowest values were for penicillin $\mathrm{MIC}=0.25 ; \mathrm{MIC}_{50}=0.44$; $\mathrm{MIC}_{90}=0.82$ against $C$. perfringens recovered from broiler chicken flocks, while values against breeder were 0.32 , 0.52 and $1 \mu \mathrm{g} / \mathrm{ml}$ respectively, followed by tylvalosin values $0.25,0.82$ and $1.2 \mu \mathrm{g} / \mathrm{ml}$ against all isolates, while the other examined antimicrobials showed high MIC values.

\section{DISCUSSION}

Necrotic enteritis (NE) caused by toxigenic strains of $C$. perfringens costs the worldwide poultry community an estimated $\$ 2$ billion annually due to costs of antimicrobial prophylaxis, loss of weight gain and inefficient feed conversion (Van Immerseel et al. 2009). Elimination of routine antibiotic use has been associated with increased incidence of NE (Cooper and Songer 2009) as the prevalence of $C$. perfringens could be attributed to the unsanitary conditions, poor hygienic measures (McClane et al. 2006). In current study the prevalence of $C$. perfringens was $37 \%$ in different Egyptian chicken flocks at which $42 \%$ in broiler, $38 \%$ in layer and $44 \%$ in breeder with high incidence in autumn $30 \%$ and in winter $26 \%$ than spring and summer which may be due to crowdedness and accumulation behavior of chickens in cold weather, also physiological stress act as an important predisposing factor to $\mathrm{NE}$ due to disturbance in corticosteroids hormones which corresponded to increased densities of $C$. perfringens in the small intestine and weight gain impairment in chickens, this emphasizes the importance of managing stress to optimize chicken health (Sarah et al. 2020).

Recently the NE pathogenesis in poultry has been the subject of considerable investigation, following identification of the novel pore forming toxin $n e t B$ on a $42 \mathrm{~kb}$ plasmid-encoded pathogenicity locus (NELoc-1) harbored specifically by NE strains (Keyburn et al. 2006; Keyburn et al. 2008) which were all highly conserved in both nucleotide and amino acid sequence (Menestrina et al. 2001) and the recovered $C$. perfringens strains from necrotic enteritis lesions were netB-positive, so these results provide a further evidence that $n e t B$ is an essential virulence factor in the pathogenesis of necrotic enteritis (Nauerby et al. 2003). There was a strong correlation between $c p b 2$ gene and netB gene (Crespo et al. 2007; Martin and Smyth 2009; Abildgaard et al. 2010). 
Int J Vet Sci, 2022, 11(1): 110-116.

Table 2: Minimum inhibitory concentration values $(\mu \mathrm{g} / \mathrm{mL})$ of Egyptian $C$. perfringens isolates harboring net-B toxin recovered from broiler, layer and breeder chicken flocks

\begin{tabular}{|c|c|c|c|c|c|c|c|c|c|}
\hline \multirow{2}{*}{$\begin{array}{l}\text { C. perfringens origin from } \\
\text { MIC values }(\mu \mathrm{g} / \mathrm{mL})\end{array}$} & \multicolumn{3}{|c|}{ Broilers } & \multicolumn{3}{|c|}{ Layers } & \multicolumn{3}{|c|}{ Breeders } \\
\hline & $\mathrm{MIC}$ & $\mathrm{MIC}_{50}$ & $\mathrm{MIC}_{90}$ & $\mathrm{MIC}$ & $\mathrm{MIC}_{50}$ & $\mathrm{MIC}_{90}$ & $\mathrm{MIC}$ & $\mathrm{MIC}_{50}$ & $\mathrm{MIC}_{90}$ \\
\hline Penicillin $\mathrm{G}$ & 0.5 & 1.5 & 1.82 & 1.5 & 2.5 & 3.6 & 2.3 & 4.2 & 4.4 \\
\hline Penicillin V & 0.25 & 0.44 & 0.82 & 0.32 & 0.48 & 0.92 & 0.32 & 0.52 & 1.00 \\
\hline Ampicillin & 0.56 & 2.1 & 2.8 & 2.2 & 3.5 & 5.5 & 2.3 & 4.2 & 8.3 \\
\hline Amoxicillin & 0.52 & 0.62 & 1.2 & 0.83 & 1.5 & 1.8 & 0.72 & 1.2 & 1.8 \\
\hline Ceftifur & 0.58 & 2.2 & 4.5 & 2.2 & 4.4 & 8.3 & 2.2 & 4.4 & 8.3 \\
\hline Bacitracin & 0.56 & 2.3 & 3.6 & 2.5 & 4.5 & 5.4 & 2.2 & 4.4 & 6.3 \\
\hline Lincomycin & 0.57 & 4.2 & 8.4 & 2.1 & 3.6 & 8.4 & 2.1 & 3.6 & 8.4 \\
\hline Tylosin & 1.2 & 2.3 & 4.4 & 1.2 & 2.3 & 4.4 & 1.2 & 2.6 & 4.2 \\
\hline Tilmicosin & 1.2 & 2.3 & 4.4 & 1.5 & 2.5 & 4.8 & 1.4 & 2.8 & 4.5 \\
\hline Tylvalosin & 0.25 & 0.82 & 1. 2 & 0.25 & 0.82 & 1. 2 & 0.25 & 0.82 & 1. 2 \\
\hline Ciprofloxacin & 2.8 & 4.3 & 8.4 & $\mathrm{R}$ & $\mathrm{R}$ & $\mathrm{R}$ & $\mathrm{R}$ & $\mathrm{R}$ & $\mathrm{R}$ \\
\hline Difloxacin & 2.8 & 4.3 & 8.4 & $\mathrm{R}$ & $\mathrm{R}$ & $\mathrm{R}$ & $\mathrm{R}$ & $\mathrm{R}$ & $\mathrm{R}$ \\
\hline Flumequine & 2.8 & 4.3 & 8.4 & $\mathrm{R}$ & $\mathrm{R}$ & $\mathrm{R}$ & $\mathrm{R}$ & $\mathrm{R}$ & $\mathrm{R}$ \\
\hline Vancomycin & 0.25 & 1.2 & 1.8 & 0.25 & 1.2 & 1.8 & 0.25 & 1.3 & 1.8 \\
\hline Rifampicin & 1.33 & 4.3 & 6.2 & 1.8 & 3.5 & 4.5 & 2.3 & 4.3 & 8.4 \\
\hline Metronidazole & 0.52 & 2.5 & 4.3 & 1.6 & 2.8 & 4.2 & 1.2 & 2.4 & 3.6 \\
\hline
\end{tabular}

R: resistant. Dilution factor: $0.25-512 \mu \mathrm{g} / \mathrm{mL}$.

NE develops when $C$. perfringens establish and multiply in the chicken's intestinal tract due to reduction of intestinal motility with mucosal damage and leakage of serum proteins into the intestinal lumen (Drew et al. 2004). C. perfringens has a generation time of 8 to $10 \mathrm{~min}$, so can increase very quickly (Stevens and Bryant 2002). In the present study, toxin typing of the recovered isolates revealed that $c p a, c p b$, etx, iap and cpe toxin in broiler isolates represent $73,25,14.5,27$ and $45 \%$, respectively and in layers were $79,66,32,37$ and $53 \%$, respectively while in breeder isolates 68, 45,18, 27 and 45\%, respectively. Toxin typing of $C$. perfringens is critical for understanding of the epidemiology criteria of $C$. perfringens infections and may be helpful in the development of effective preventive measures (Nowell et al. 2010) as the release of these toxins is believed to play a major role in determining pathogenesis properties of $C$. perfringens (Ronco et al. 2017). Datta et al. (2014) showed that out of $30 \mathrm{C}$. perfringens isolates from healthy birds, $33.3 \%$ were positive for $\alpha$ toxin alone and $6.7 \%$ for $\beta-2$ toxin alone. In addition, seven (23.3\%) isolates were positive for both $\alpha$ and $\beta-2$ toxins. In case of the diseased birds, $16(53.3 \%)$ isolates were positive for alpha toxin alone and $2(6.7 \%)$ for $\beta-2$ toxin alone. Ten $(33.3 \%)$ isolates were positive for both $\alpha$ and $\beta-2$ toxins. Thus, 19 and 28 isolates from healthy and diseased birds respectively were toxin producing. Agrawal made similar observations et al. (2009) who reported $39.2 \%$ isolates of C. perfringens to be positive for $\alpha$ toxin alone and $32.10 \%$ isolates were positive for both $\alpha$ and $\beta$ toxins. Fan et al. (2016) reported that the $C$. perfringens type A isolates expressed only the cpa gene encoding for alpha toxin. Several studies have indicated that cpe-positive strains of C. perfringens from poultry occur in low number and can be less than 5\% of global C. perfringens isolates (Zhang et al.2018). This study showed that the presence of $\alpha$ and $\beta-2$ toxin producing strains of $C$. perfringens in healthy as well as enteritis-affected broiler chickens. There was an increase in number of the toxin producing isolates from diseased birds.

Higher percentage of $\alpha$ and beta- 2 toxin gene producing $C$. perfringens strains in diseased broiler birds indicates its possible role in pathogenesis of enteritis.
Alpha toxin hydrolyzes lecithin a major component of the cell membrane and thus destroys the red blood cells, platelets and muscles leading to the myonecrosis. Beta toxin induces hemorrhagic necrosis of the intestinal mucosa. Australian strain of $C$. perfringens type A harbored NetB was isolated from necrotic enteritis (NE) affected broiler chicken (Keyburn et al. 2010). In the present study, traceability of net-B toxins in the recovered isolates showed that net-B toxin distribution in broiler isolates $82 \%$, layer isolates $89 \%$ and breeder isolates $90 \%$. Sequencing of three isolates and accessesion numbers on Genbank and under code: MW925054 from broiler, MZ382848 from layer and MW925055 from breeder chicken flock respectively. Net-B is a pore forming toxin with structure equal to 3.9 Angstrom (Savva et al. 2013), which can damage the phospholipid membrane bilayer of both human and animal cells, causing an influx of ions (i.e., $\mathrm{Na}+\mathrm{Cl}, \mathrm{Ca} 2+$ that leads to osmotic cell lysis (Keyburn et al. 2010; Sergio et al. 2014). Interestingly, all netB-positive isolates were from flocks with the subclinical form of NE, with a moderate increase of mortality rate but an absence of typical pathologic findings of enteritis. In contrast, when severe NE was observed during autopsy of deceased birds, no netB gene was detected (Francesca et al. 2019).

Antibiotic as $\beta$-lactams, aminoglycosides, macrolides and tetracyclines used in broiler farms for therapeutic purposes of enteric diseases, particularly necrotic enteritis Penicillins as a $\beta$-lactams members are known to be particularly active against $C$. perfringens as resistance against penicillin is very rare and $\beta$-lactamase has not been demonstrated with three days as minimum duration of treatment, however longer applications may be required (Hughes et al. 2008). In the current study, the antimicrobial sensitivity test showed that all isolates were $100 \%$ sensitive for penicillin, amoxicillin, tylvalosin and vancomycin, while were resistant for clindamycin, spiramycin, oxytetracycline, doxycycline, chlortetracycline, colistin, florphenicol, spectinomycin, neomycin, gentamycin, streptomycin and trimethoprim-sulfamethoxazole. Recently, Gad et al. (2011) determined MIC of 16 antibiotics for 100 C. perfringens isolates collected between 2008 and the results revealed that there were no 
isolates were resistant $\beta$-lactam antibiotics, lincospectin, tylosin, doxycycline, tetracycline, trimethoprim/ sulfamethoxazole, lincomycin, and tilmicosin with low frequency of resistance was detected against erythromycin and tiamulin with 5 and $20 \%$, respectively, while the highest incidence of resistance were spectinomycin, neomycin and colistin with 74, 94 and $100 \%$, respectively. In economic point of view controlling of necrotic enteritis cases even clinical or subclinical form in commercial poultry flocks become urgent to overcome its losses in body weight gain and costs of medication (Kaldhusdal and Løvland 2000; Skinner et al. 2010), so strategies to reduce the incidence of clostridial infections become important to avoid economic losses and increase the profitability (McReynolds et al. 2009).

Finally, the present study survey of the minimum inhibitory concentration of net- $B$ toxins isolates at which the lowest values were for penicillin $\mathrm{MIC}_{90}=0.82$ against C. perfringens recovered from broiler chickens flocks, while values against layers and breeders were $1 \mu \mathrm{g} / \mathrm{ml}$ respectively, followed by tylvalosin $\mathrm{MIC}_{90=1.2 \mu \mathrm{g} / \mathrm{ml}}$ against all isolates, while the other examined antimicrobials showed variable values. Resistance of $C$. perfringens the most common antibiotics become recorded (Shojadoust et al. 2010), and also there were MDR isolates as detected in Iran $34.17 \%$ (Akhi et al. 2015), this may be due to the wide spread of the antimicrobials in combating infections. Resistance rate of C. perfringens to tetracycline 66and $56.2 \%$ (Tansuphasiri et al. 2005) and $87.5 \%$ to neomycin (Shojadoust et al. 2010), while the percentage of resistance to $\beta$-lactams was less than 7\% (Silva et al. 2014; Hamza et al. 2017; Chon et al. 2018; Mwangi et al. 2019).

\section{Conclusion}

C. perfringens has been shown to develop multiple drug resistance mainly in winter and autumn season, indicating that the treatment for this bacterium is quite challenging, so must depend on MICs values for common used antibiotics which revealed that penicillin is the drug of choice against isolates from different flocks.

\section{Author's Contribution}

All authors contributed equally to study the design methodology, interpretation of results, and writing of the manuscript.

\section{Acknowledgment}

We gratefully thank Dr. Moatasem Nowara, the Chairman of MN Trade Veterinary Pharmaceutical Company for antibiotic supply.

\section{REFERENCES}

Abildgaard L, Sondergaard TE, Engberg RM, Schramm A and Højberg O, 2010. In vitro production of necrotic enteritis toxin B, NetB, by netB-positive and netB-negative Clostridium perfringens originating from healthy and diseased broiler chickens. Veterinary Microbiology 144: 231-235. https://doi.org/10.1016/j.vetmic.2009.12.036

Agrawal A, Narang G, Rakha NK, Mahajan NK and Sharma A, 2009. In vitro lecithinase activity and antibiogram of Clostridium perfringens isolated from broiler chickens. Haryana Veterinary 48: 81-84.
Awaad MHH, Elmenawey MA, Afify MA, Zouelfekar SA, Mohamed FF and Demy V, 2019. The impact of high stocking density and Saccharomyces cerevisiae boulardii on productive performance, intestinal microbiota and gut integrity of broiler chickens. International Journal of Veterinary Science 8: 362-370.

BSAC, 2011. Methods for antimicrobial susceptibility testing, Version 10.2, May 2011. British Society for Antimicrobial Chemotherapy, Birmingham, United Kingdom.

Chon JW, Seo KH, Bae D, Park JH, Khan S and Sung K, 2018. Prevalence, toxin gene profile, antibiotic resistance, and molecular characterization of Clostridium perfringens from diarrheic and non-diarrheic dogs in Korea. Journal of Veterinary Science 19: 368-374. https://doi.org/10.4142/ jvs.2018.19.3.368

CLSI, 2018. M11, Methods for Antimicrobial Susceptibility Testing of Anaerobic bacteria. 9th Ed. Clinical Laboratory Standards Institute. Available at https://clsi.org/media/2577/m11-ed9_sample

Collins MD, Lawson PA, Willems A, Cordoba JJ, FernandezGarayzabal J and Garcia P, 1994. The phylogeny of the genus Clostridium: proposal of five new genera and eleven new species combinations. International Journal of Systematic and Evolutionary Microbiology 44: 812826. https://doi.org/10.1099/00207713-44-4-812

Cooper KK and Songer JG, 2009. Necrotic enteritis in chickens: A paradigm of enteric infection by Clostridium perfringens type A. Anaerobes 15: 55-60. https://doi.org/ 10.1016/j.anaerobe.2009.01.006

Crespo R, Fisher DJ, Shivaprasad HL, FernandezMiyakawa ME and Uzal FA, 2007. Toxinotypes of Clostridium perfringens isolated from sick and healthy avian species. Journal of Veterinary Diagnostic Investigation 19: 329-333. https://doi.org/ 10.1177/104063870701900321

Datta S, Rakha NK, Narang G, Arora D and Mahajan NK, 2014. Prevalence of $\alpha, \beta$ and Net B toxins producing strains of clostridium perfringens in broiler chicken in Haryana. Haryana Veterinary Journal 53: 39-42

Drew MD, Syed NA, Goldade BG, Laarveld B and Van Kessel AG, 2004. Effects of dietary protein source and level on intestinal populations of Clostridium perfringens in broiler chickens. Poultry Science 83: 414-420. https://doi.org/ $10.1093 / \mathrm{ps} / 83.3 .414$

Fan YC, Wang CL, Wang C, Chen TC, Chou CH and Tsai HJ, 2016. Incidence and antimicrobial susceptibility to Clostridium perfringens in Premarket broilers in Taiwan. Avian Diseases 60: 444-449. https://doi.org/10.1637/ 11315-110915-Reg

Fossum O, Sandstedt K and Engström BE, 1988. Gizzard erosions as a cause of mortality in white leghorn chickens. Avian Pathology 17: 519-525. https://doi.org/10.1080/0307 9458808436471

Francesca P, Cristina E, Di Francesco DI and Andrea Di ,2019. Prevalence of netB-positive Clostridium perfringens in Italian poultry flocks by environmental sampling. Journal of Veterinary Diagnostic Investigation 32: 252 258. https://doi.org/10.1177/1040638719885841

Gabriel I, Mallet S and Leconte M, 2003. Differences in the digestive tract characteristics of broiler chickens fed on complete pelleted diet or on whole wheat added to pelleted protein concentrate. British Poultry Science 44: 283-290. https://doi.org/10.1080/0007166031000096470

Gad W, Hauck R, Krüger $M$ and Hafez HM, 2011. Determination of antibiotic sensitivities of Clostridium perfringens isolates from commercial turkeys in Germany in vitro. European Poultry Science 75: 80-83.

Garmory HS, Chanter N, French NP, Bueschel D, Songer JG and Titball RW, 2000. Occurrence of Clostridium perfringens beta2-toxin amongst animals, determined using genotyping and subtyping PCR assays. Epidemiology 
and Infection 124: 61-67. https://doi.org/10.1017/s0950268 $\underline{899003295}$

Hamza D, Dorgham S and Hakim A, 2017. Toxinotyping and antimicrobial resistance of Clostridium perfringens isolated from processed chicken meat products. Journal of Veterinary Research 61: 53-58. https://doi.org/10.1515/ jvetres-2017-0007

Hatheway CL, 1990. Toxigenic clostridia. Clinical Microbiology Review 3: 66-98. https://doi.org/10.1128/cmr.3.1.66

Hughes L, Hermans P and Morgan K, 2008. Risk factors for the use of prescription antibiotics on UK broiler farms. Journal of Antimicrobial Chemotherapy 61: 947-952. https://doi.org/10.1093/jac/dkn017

Jihong L, Daniel P, Mahfuzur RS, and Clane BAM ,2016. Clostridium perfringens Sporulation and SporulationAssociated Toxin d Toxin Production. Microbiology Spectrum Journal, 4: 1-26. http://www.doi.org/10.1128/ microbiolspec.TBS-0022-2015

Kaldhusdal M and Løvland A, 2000. The economical impact of Clostridium perfringens is greater than anticipated. World Poultry 16: 50-51.

Kaldhusdal M and Hofshagen M, 1992. Barley inclusion and avoparcin supplementation in broiler diets. Clinical, pathological and bacteriological findings in a mild form of necrotic enteritis. Poultry Science 71: 1145-1153. https://doi.org/10.3382/ps.0711145

Kanakaraj R, Harris DL, Songer JG and Bosworth B, 1998. Multiplex PCR assay for detection of Clostridium perfringens in feces and intestinal contents of pigs and in swine feed. Veterinary Microbiology 63: 29-38. https://doi.org/10.1016/s0378-1135(98)00229-6

Keyburn AL, Boyce JD, Vaz P, Bannam TL, Ford ME and Parker D, 2008.NetB, a new toxin that is associated with avian necrotic enteritis caused by Clostridium perfringens. PLoS Pathogen 4: e26. https://doi.org/10.1371/ journal.ppat.0040026

Keyburn AL, Sheedy SA, Ford ME, Williamson MM and Awad MM, 2006. Alpha-Toxin of Clostridium perfringens is Not an Essential Virulence Factor in Necrotic Enteritis in Chickens. Infection and Immunity 74: 6496-6500. https://doi.org/ 10.1128/IAI.00806-06

Keyburn AL, Bannam TL, Moore RJ and Rood JI, 2010. Net B, a pore-forming toxin from necrotic enteritis strains of Clostridium perfringens. Toxins 2: 1913-1927. https://doi.org/10.3390/toxins2071913

Koneman EW, Allen SD, Janda WM, Schreckenberger PC and Winn WJ,1997. Color Atlas and Textbook of Diagnostic Microbiology. 5th Ed. Philadelphia: Lippincott Williams and Wilkins, pp: 709-784.

Martin TG and Smyth JA, 2009. Prevalence of netB among some clinical isolates of Clostridium perfringens from animals in the United States. Veterinary Microbiology 136: 202-205. https://doi.org/10.1016/j.vetmic.2008.10.026

McClane B, Lyerly DM and Wilkins TD, 2006. Chapter 57: Enterotoxic clostridia: Clostridium perfringens type A and Clostridium difficile. In: Gram-Positive Pathogens, $2^{\text {nd }}$ Ed, Wiley Online Library pp: 703-714. https://doi.org/10.1128/ 9781555816513.ch57

McReynolds J, Waneck C, Byrd J, Genovese K, Duke S and Nisbet D, 2009. Efficacy of multistrain direct-fed microbial and phytogenetic products in reducing necrotic enteritis in commercial broilers. Poultry Science 88: 2075-2080. https://doi.org/10.3382/ps.2009-00106

Menestrina G, Serra MD and Prevost G, 2001. Mode of action of beta-barrel pore-forming toxins of the staphylococcal alpha-hemolysin family. Toxicon 39: 1661-1672. https://doi.org/10.1016/s0041-0101(01)00153-2

Mwangi S, Timmons J, Fitz-Coy S and Parveen S, 2019. Characterization of Clostridium perfringens recovered from broiler chicken affected by necrotic enteritis. Poultry Science 98: 128-135. https://doi.org/10.3382/ps/pey332

Nauerby B, Pedersen K and Madsen M, 2003. Analysis by pulsed-field gel electrophoresis of the genetic diversity among Clostridium perfringens isolates from chickens. Veterinary Microbiology 94: 257-266. https://doi.org/ 10.1016/s0378-1135(03)00118-4

Nowell N, Poppe C and Parreira VR, 2010. Clostridium perfringens in retail chicken. Anaerobes 16: 314-315. https://doi:10.1016/j.anaerobe.2009.11.004

Perelman B, Mints S, Zjut M, Kuttin E and Machny S, 1991. An unusual Clostridium colinum infection in broiler chicken. Avian Pathology 20: 475-480. https://doi.org/10.1080/ $\underline{03079459108418785}$

Prescott JF, Parreira VR, Mehdizadeh GI, Lepp D and Gong J, 2016. The pathogenesis of necrotic enteritis in chickens: what we know and what we need to know: A review. Avian Pathology 45: 288-294. https://doi:10.1080/03079457. 2016.1139688

Randall CJ, Sasaki J, Goryo M and Okada K, 1991. A Colour Atlas of Diseases and Disorders of the Domestic Fowl and Turkey, 2nd Ed. Wolfe Publishing Ltd pp: 134-135.

Ronco T, Stegger M, Ng KL, Lilje B, Lyhs U, Andersen PS and Pedersen K, 2017. Genome analysis of Clostridium perfringens isolates from healthy and necrotic enteritis infected chickens and Turkeys. BMC Research Notes 10: 270. https://doi: 10.1186/s13104-017-2594-9

Sarah JM, Sarah M, Alexander M, Richard RE, Wesley F, Wade Abbott D and Douglas IG, 2020. Host responses to Clostridium perfringens challenge in a chicken model of chronic stress. Gut Pathogens 10: 12-24. https://doi.org/ 10.1186/s13099-020-00362-9

Sasaki J, Goryo M and Okada K, 2000. Cholangiohepatitis in chickens induced by bile duct ligations and inoculation of Clostridium perfringens. Avian Pathology 29: 405-410. https://doi.org/10.1080/030794500750047144

Savva CG, Fernandes da Costa, Bokori-Brown M, Naylor CE, Cole AR, Moss DS, Titball RWand Basak AK, 2013. Molecular architecture and functional analysis of NetB, a pore-forming toxin from Clostridium perfringens. Journal of Biological Chemistry 288: 35123522 https://doi:10.1074/jbc.M112.430223

Sergio P, Fernandes da Costa, Savva CG, Bokori-Brown M, Claire E, Naylor, Moss DS, Basak AK and Titball RW, 2014. Identification of a key residue for oligomerisation and pore-formation of Clostridium perfringens NetB Toxins 6: 1049-1061. https://doi.org/10.3390/toxins6031049

Shojadoust B, Peygambari S and Nik PH, 2010. Isolation, identification, and antimicrobial susceptibility of Clostridium perfringens isolates from acute necrotic enteritis of broiler chickens. International Journal of Veterinary Science 4: 147-151. https://doi:10.22059/ IJVM.2010.21344

Silva ROS, Ferreira Junior FC, Marques MVR, Oliveira Junior CA, Martins NRdS and Lobato FCF, 2014. Genotyping and antimicrobial susceptibility of Clostridium perfringens isolated from Tinamidae, Cracidae and Ramphastidae species in Brazil. Ciência Rural 44: 486-491. https://doi.org/10.1590/S0103-84782014000300016

Skinner JT, Bauer S, Young V, Pauling G and Wilson J, 2010. An economic analysis of the impact of subclinical (mild) necrotic enteritis in broiler chickens. Avian Diseases 54: 1237-1240. https://doi.org/10.1637/9399-052110-Reg.1

Stevens DL and Bryant AE, 2002. The role of clostridial toxins in the pathogenesis of gas gangrene. Clinical Infectious Diseases 35: S93-S100. https://doi.org/10.1086/341928

Tansuphasiri U, Matra W and Sangsuk L, 2005. Antimicrobial resistance among Clostridium perfringens isolated from various sources in Thailand. Southeast Asian Tropical Medicine and Public Health 36: 954-961 
Int J Vet Sci, 2022, 11(1): 110-116.

Timbermont L, Lanckriet A, Gholamiandehkordi AR, Pasmans F, Martel A and Haesebrouck F, 2009. Origin of Clostridium perfringens isolates determines the ability to induce necrotic enteritis in broilers. Comparative Immunology, Microbiology and Infectious Diseases 32: 503-512. https://doi.org/10.1016/j.cimid.2008.07.001

Titball RW, Naylor CE, Miller J, Moss DS and Basak AK, 2000. Opening of the active site of Clostridium perfringens alphatoxin may be triggered by membrane binding. International Journal of Medical Microbiology 290: 357-361. https://doi.org/10.1016/s1438-4221(00)80040-5

Van Immerseel F, Rood JI, Moore RJ and Titball RW, 2009. Rethinking our understanding of the pathogenesis of necrotic enteritis in chickens. Trends in Microbiology 17: 32-36. https://doi.org/10.1016/j.tim.2008.09.005
Yegani M and Korver D, 2007. Application of egg yolk antibodies as replacement for antibiotics in poultry. World's Poultry Science Journal 66: 27-38. https://doi.org/10.1017/ $\underline{\mathrm{S} 0043933910000048}$

Yoo HS, Lee SU, Park KY and Park YH, 1997. Molecular typing and epidemiological survey of prevalence of Clostridium perfringens types by multiplex PCR. Journal of Clinical Microbiology 35: 228-232. https://doi.org/ 10.1128/jcm.35.1.228-232.1997

Zhang T, Zhang W, Ai D, Zhang R, Lu Q, Luo Q and Shao H, 2018. Prevalence and characterization of Clostridium perfringens in broiler chickens and retail chicken meat in central China. Anaerobe 54: 100-103. https://doi.org/ 10.1016/j.anaerobe.2018.08.007 